\title{
Inclusion as heterotopia: Spaces of encounter between people with and without intellectual disability
}

\section{Herman P. Meininger}

VU University Amsterdam

\begin{abstract}
The public space to which - in line with common definitions of inclusion - persons with intellectual disability are designated often turns out to be a space of discrimination. The aim of this study is to identify spaces of encounter. Michel Foucault's concept of heterotopia - 'other spaces' - and its subsequent interpretations are used as an analytical tool for evaluating efforts to include persons with intellectual disability in society. In Foucault's work 'space' refers to geographical places and to 'sites' that can be defined by sets of relations. Among these spaces are 'counter-sites' like large scale residential facilities for people with intellectual disability. Though policies of deinstitutionalisation aim at erasure of these places of exclusion, the results are often disappointing, largely because these policies ignore the analysis of power dynamics that install exclusionary processes and structures. Recent interpretations of the concept of heterotopia position the 'other places' in the middle of ordinary life as social spaces of encounter and dialogue between the 'normal' and the 'abnormal'. Characteristics and practical conditions of such spaces of encounter are explored. These interpretations open up a new conceptualisation of inclusion in terms of niches in which encounter and dialogue are cultivated and an alternative social ordering can be exercised.
\end{abstract}

Keywords: Foucault, space, intellectual disability, inclusion, deinstitutionalization, encounter 


\section{Introduction}

Step by step people with intellectual disability have become more visible in society. Processes leading in this direction are labelled as deinstitutionalisation, normalisation, integration or inclusion and various political or social scientific definitions of these terms are proposed (Crisp, 2010; Taket et al., 2009, pp. 99-100). At the centre of all these definitions is the moral rejection of former policies and practices that resulted in persons with intellectual disability living segregated from their families, local communities and society at large. For many years inclusion has been proclaimed as the central idea of policy, management and practice of service provision for people with intellectual disability. However, the conceptualization and the moral presuppositions of this policy have not been clear or were very limited (Clegg, Murphy, Almack, \& Harvey, 2008; Cobigo, Ouellette-Kuntz, Lysaght, \& Martin, 2012; Hall, 2010; Martin \& Cobigo, 2011). Therefore its implementation is sometimes judged as half-hearted and inconsiderate (Tøssebro et al., 2012). Also, in activism and research the meaning of concepts of community and of participation may vary significantly, and sometimes even be contradictory (Carey, 2011).

Often, the concept of 'community care' is based on an 'imagined community' or an idealised view of the 'good life' (Carey, 2011; Gleeson \& Kearns, 2001). It can mean almost anything but the traditional care in large-scale residential facilities, regardless the fact that in reality such caring communities hardly exist (Ben-Moshe, 2011). That does not surprise considering Zygmunt Bauman's statement: "What that word evokes is everything we miss and what we lack to be secure, confident and trusting [...]. 'Community' is nowadays another name for paradise lost - but one to which we dearly hope to return" (Bauman, 2001, p. 13). In the meantime, many people with intellectual disability have left the institutions, the geographically located symbols of their exclusion. We know that community participation has to do with places, people, and the sense of belonging or exclusion that may emerge from their interaction (Bray \& Gates, 2003). But the question is: do people labelled as having intellectual disability really meet, connect and associate with other people? In what kind of places does this happen? And what does such an inclusion mean for society at large?

In this paper I will reflect on more basic and abstract concepts like space (community as some kind of space) and encounter (participation always implies 
some kind of encounter). This reflection will be based on a description of 'heterotopia' - 'other spaces' - as conceptualized by Michel Foucault and of some subsequent interpretations of this concept. 'Heterotopia' and its interpretations will be used to analyse developments in systems of care for and support of persons with intellectual disability with a special focus on policies and practices of inclusion. It will be argued that the concept of 'heterotopia' opens up a new space of encounter that transcends spaces that are geographically positioned or related to a specific life domain. This new space is a social space consisting in a continuing dialogue between the 'normal' and the 'abnormal', the familiar and the strange. Characteristics of such spaces of encounter will be outlined. Finally, I will make some remarks about the relation of spaces of encounter with society at large and its policies and practices of inclusion.

When I use the term 'intellectual disability' in this article, the reader should bear in mind that - as Goodey's (2011) historical work has convincingly shown 'intelligence' is above all a historically contingent status concept, originating from the urge to get certainty about one's social position by classifying, ranking, and distinguishing human beings from each other. As a consequence 'intellectual disability' and its ever changing definitions are the outcome of complex power relations (Carlson, 2010).

\section{Sites and counter-sites}

For these reflections on spaces of encounter I was inspired by a lecture of the French philosopher Michel Foucault entitled 'Other Spaces'. The lecture was delivered as a radio conference for France Culture in December 1966. The original French text of this radio conference was recently published under the title 'Les Héterotopies' (Defert, 2009; Foucault, 2009). Stenographic notes of a reworked version, presented at a meeting of the 'Cercle d'études architecturales de Paris' in 1976, were first published in 1984 (Foucault, 1984), and then translated in English (Foucault \& Miskowiec, 1986). The lecture sparked off a widespread debate. The most active international discussions following the publication of Foucault's lecture about what he calls 'heterotopia' have taken place within the field of social geography and the theory of architecture (Dehaene \& De Caulter, 2008). But in recent years there has also been a growing interest in other disciplines like theology, social theory, sociology and ethics. From these perspectives 'other places' or 'places 
of otherness' can also be understood as a certain kind of events, cultural practices, relationships or even discourses and texts (Hetherington, 1997). Care and support practices for marginalized people have become one of the fields that have been analysed in the light of heterotopic thinking (Wyller, 2009).

Foucault observes in his ground-breaking lecture - in this article I cite from the 1986 English translation - that in the Middle Ages space was defined as the space of emplacement. There was 'a hierarchic ensemble of spaces': sacred places and profane places; protected places and open, exposed places; urban places and rural places. In cosmological theory there were the super-celestial places, as opposed to the celestial, and the celestial place was in its turn opposed to the terrestrial place. There were places where things had been put because they had been violently displaced, and on the contrary places where things found their natural ground and stability. After Galileo Galilee's rediscovery that the earth revolved around the sun a thing's place was no longer anything but a point in its movement, just as the stability of a thing was only its movement indefinitely slowed down. The emplacement of things that in mediaeval physics was thought of in terms of extension is now thought in terms of localization. At the same time places have - at least theoretically - been desanctified or as we would call it: secularized. Localized space is called by Foucault 'site'. A site is defined by relations of proximity between points or elements; formally these relations can be described as series, trees or grids. 'Our epoch is one in which space takes for us the form of relations among sites' (Foucault \& Miskowiec, 1986, p. 23). More concrete, the problem of the human site or living place is that of knowing what relations of propinquity, what type of storage, circulation, marking and classification of human elements should be adopted in a given situation in order to achieve a given end.

This does not mean at all that nowadays we have left behind the sacrosanct oppositions and intersections that characterized mediaeval thought. According to Foucault many oppositions that most of us uncritically accept as simple givens are still nurtured by the 'hidden presence of the sacred'. He mentions the opposition between private and public space, between family space and social space, between cultural space and useful space, between the space of leisure and that of work. Thus, space is heterogeneous. It is not a void that we can manipulate or form by placing things or persons in it any way we like; we live inside a set of relations that 
delineates sites which cannot be reduced to or superimposed on one another. Foucault mentions the examples of the sites of transportation (streets, trains), sites of temporary relaxation (cafés, cinemas, beaches) and the closed or semi-closed sites of the house, the bedroom, the bed, etcetera (Foucault \& Miskowiec, 1986, p. 24).

Now Foucault is mainly concerned with what he calls 'counter-sites' or 'heterotopia', sites or places that "...have the curious property of being in relation to all the other sites, but in such a way as to suspect, neutralize, or invert the set of relations that they happen to designate, mirror or reflect" (Foucault \& Miskowiec, 1986 , p. 24). Counter-sites or heterotopia are places found in every culture and yet different from any other place they mirror by representing, contesting or inverting the places that constitute the 'homotopia', the space in which we live, 'real' space, 'normal' space. So heterotopia are by definition in a relation of critique to the rest of society. The most well known examples of this classical concept of heterotopia are prisons, psychiatric hospitals and residential institutions for people with intellectual disability, all objects of Foucault's genealogical studies and labelled by Erving Goffman as 'total institutions'. Both Foucault and Goffman consider these heterotopia to be symptoms of a society that strives to exclude all kinds of deviance (Foucault, 2006; Goffman, 1961).

As Kitchin (1998) observes in relation to people with a disability, these spaces are constructed to keep disabled people 'in their place', at the same time conveying to them the message that they are 'out of place' and teaching them to 'know their place'. For Foucault, however, an important paradox of the disciplined society is that the people silenced and distanced to the heterotopia nevertheless maintain powerful positions. They do so by being 'others', by occupying the spaces that normality has abandoned, the anomalous zones designed to control any form of 'aberrancy', the spaces that continuously criticize the self-propelling power of the othering and excluding normality (Razack, 2002). This normality is usually represented as natural and essential, but Foucauldian analysis shows that normality and its implied able/not able divide (or divisions based on race, gender or ethnicity) refer to the contingent outcome of complex power relations between people labelled as 'intellectually disabled' and those in positions of power (parents, advocates, physicians, psychologists, service providers) (Carlson, 2010, pp. 99-101). 


\section{Developments in care and support}

Looking back at the developments of the last four decades in care and support of persons with intellectual disability a continuing process of deinstitutionalisation and a pursuit of inclusion can be observed. The geographically positioned places of exclusion, the institutions, have been dismantled for the greater part. The UN Convention on the Rights of Persons with Disabilities has been adopted, though not ratified, let alone implemented by almost all governments (UN, 2006). It seems that great steps have been taken in the erasure of our 'other places' of exclusion. Citizenship, mainstreaming, self-determination, autonomy and equality are key pillars of the inclusion processes that have been started off. Foundational thought in these processes seems to be that those who were excluded must in one way or another be brought back from the periphery into a homogenized and idealized centre of society. More than often, this development is pictured as a fundamental break with the delusions and even inhumanity of former times. As Gleeson \& Kearns stated: "Deinstitutionalisation has been constituted through discourses about places, about good and bad places - about moral landscapes" (Gleeson \& Kearns, 2001, p. 72).

The actual service landscape in the field, however, shows the emergence of a great variety of facilities that can hardly be differentiated along the lines of good or bad. They range from small-scale protective asylum-like services to sheltered villages and supported or independent living settings. Most of them show a poignant lack of community participation or community integration, since the nineties labelled as inclusion (Cummins \& Lau, 2003). Many policies of deinstitutionalisation have resulted in a continuation of institutional regimes and routines within different, more or less dispersed and individualized, housing arrangements. Despite these policies most people with intellectual disability still spend their school, work and leisure time in sheltered and segregated settings. Many people with intellectual disability prefer to befriend with other people with intellectual disability and do not see particular benefits in their presence to the general public. Though housing arrangements have improved enormously, most people with intellectual disability have a very limited choice in where to live and with whom. The scale of their living arrangements is hardly ever determined by their own choice but by the demands of cost-effective management of service organizations. Empirical research suggests that social inclusion as ultimate goal of deinstitionalisation has hardly been realized even in 
situations of full physical and geographical integration (Cummins \& Lau, 2003; Verdonschot, De Witte, Reichrath, Buntinx, \& Curfs, 2009a, 2009b).

Spatial (re)location in itself does not seem to be a necessary or sufficient condition for community participation and having social relationships. Recently, in the UK, Norway, New Zealand and Australia retrenchment in community services has led to larger scale settings being provided and in some areas new institutions are being built, cost-effectiveness being the leading principle of this policy (BeadleBrown, Mansell, Tøssebro, Siska, \& Bigby, 2011; Burrel \& Trip, 2011; Tøssebro et al., 2012). This circumstance confirms Edward Hall's earlier analysis that '...social inclusion policy and alternative networks of inclusion both perpetuate exclusion, as the discriminatory contexts are left unchanged and inclusion within people with learning disability networks ignores broader exclusionary processes' (Hall, 2005, p. 113).

As a consequence of this ignorance of exclusionary processes persons with intellectual disability were readily cast in the mould of the modern self confident, assertive citizen as manifestation of a diversified but universal humanity (Hall, 2010). Their otherness was disregarded, denied or reinterpreted as just another variety of the human species. In terms of Jayne Clapton: The 'Technical' inclusion that focuses on technologies that are needed to facilitate community living and the 'Legislative' inclusion that focuses on a rights discourse asserting ideals of autonomy, independence and egalitarian citizenship, both fell short of adequately redressing the 'Profound' exclusion expressed in religious and moral thinking, in political, philosophical and ethical theorising and in service practice (Clapton, 2009, pp. 211225). Some policies of inclusion can even be interpreted as new and ingenious ways of masking society's deep-rooted responses to deviance and its coherent disciplinary mechanisms. Joel Kahn (Kahn, 2001, p. 23) points to the paradox that, because of its embeddedness in concrete and historical circumstances, the modern idea of a universal humanity, encompassing all diversity, as expressed in rationality and autonomy, always has its 'others' and thus brings with it processes of social exclusion.

Many policies of inclusion have failed in the end because they amount to what Stiker (1999) has called a 'technocracy of absorption'. Not just because the moral imperatives implied by such policies are only partially endorsed by people with 
intellectual disability and their families (Clegg et al., 2008; Gleeson \& Kearns, 2001), not only because most people with intellectual disability still belong to the lowest socio-economical strata in all societies, but mainly because we have not been able to deconstruct the mental representations of deviance that foster social resistance against and exclusion of people who are different (Snyder \& Mitchell, 2006). For instance, research of inclusion policy documents and teacher's discourse in mainstream schools attended by children with disabilities revealed that both documents and discourse drew upon individual tragedy models of disability and intervention models of a 'pseudo-medical' character underpinned by the assumption of a 'normally developing child' (Holt, 2003; Lalvani, 2013). Surely, we have gained a lot by involving people with intellectual disability in ordinary life, but the question is whether we have been aware of the inherent normative character of the ordinariness of so called 'normal' life. The disciplining power that manifested itself in the institutions of the nineteenth and twentieth century has not disappeared. It only has taken a different face. Therefore, it is highly plausible to analyse social inclusion as a strategy of power to produce well integrated citizens (Drinkwater, 2005).

\section{A heterotopic perspective}

From the perspective of policy makers it may appear that the geographically situated spaces of deviance, the concrete 'other spaces' of institutions, are in the process of being erased. However, the perspective of the heterotopic thinking of Foucault shows that the disciplining monocultures controlled by professionals that were characteristic for these institutions have not at all been driven back. The exclusionary processes that are the sources of the Foucauldian heterotopia are not eliminated when institutions are dismantled. These processes appear to have profound cultural roots that cannot simply be circumvented by a change of living conditions, no matter how justified the moral appeal for such a change may be. The neglect of this 'profound exclusion' goes hand in hand with a lack of awareness of the opening up of a new heterotopic space, this time a space that is not really materially limited like an institution, a house, a room or a city (Gleeson, 2001). This new heterotopic space is deterritorialized. It does not refer to places that are demarcated by visible borders, but it consists in relations between people who live on the margins and people who live in the centre of civil society (Villadsen \& Wyller, 2009). 
The new heterotopos is not a concrete geographical space somewhere on the verges of or segregated from 'normal' society. It is a relational space. It is a space of encounter, where people who are 'other' to each other meet and communicate (Meininger, 2010). Foucault and his discussants in social geography and architecture still located heterotopia in concrete rooms, houses and institutions. Recent interpretations go some steps further by underlining that the heterotopic can be found everywhere, even in those places that geographically, architecturally, legally and politically are 'mainstream'. Heterotopos then does not refer anymore to a place, but to a dimension of human social reality. It is an idea about space rather than an actual place. The question is how one participates in it and whether one is being confronted, touched and changed by it (Villadsen \& Wyller, 2009, p. 221). Kevin Hetherington concludes his critical analysis of Foucault's writings on heterotopia and space with this summary (Hetherington, 1997, p. 51):

- Heterotopia cannot be described as fixed spaces.

- Heterotopia always have multiple and shifting meanings for agents depending on where they are located within its power effects.

- Heterotopia are always defined relationally to other sites or within a spatialization process, and never exist for themselves.

- Heterotopia, if they are taken as relational, must have something distinct about them, something that makes them an obligatory point of passage.

- Heterotopia are not about resistance or order but can be about both because both involve the establishment of alternative modes of ordering.

For Hetherington the last two points are the most important: the distinctive character of heterotopia as obligatory points of passage and the ambiguity of heterotopia as sites of both criticism of established social ordering and the development of alternative social ordering. These points express the key characteristic of this conceptualisation of heterotopia: the encounter with 'the other' and with 'otherness'. Hetherington thus looks upon heterotopia as nurseries of social change: "The alternative mode of ordering expressed in a heterotopic site is a mode of ordering based upon some idea of social improvement" (p. 52).

Though these new interpretations of Foucault's conceptualization of heterotopia continue to embrace the classical elements of both exclusion based on 
deviance and a critical mirroring and thus disordering of our usual ways of life, several remarkable shifts can be observed. Heterotopia are not anymore depicted as merely a geographical reality, but as a social, relational, cultural and spiritual one. The relational character has an internal and an external dimension. Heterotopia are about relationships between people and heterotopia themselves stand in relation to other spaces from which they are distinguished. In a spiritual sense these authors do not interpret heterotopia as spaces that are unequivocally abandoned by normality, but as ambiguous mixtures of the normal and the abnormal, the reasonable and the insane, the familiar and the strange, the proper and the improper (Macfarlane, 2010). These new heterotopia are distinguished from homotopia by their devotion to dialogue between the normal and the abnormal, order and disorder, the reasonable and the insane, the familiar and the strange. This makes heterotopia deviant from 'real' or 'normal' space that in its self-closed monologue unremittingly wallows in the illusion that all otherness can be banned or at least managed by therapeutic, technical, or legal means. By this dialogue heterotopia develop into spaces of experiment with new models of interaction, communication, connection, participation and power relationships, into laboratories of new meaning and of alternative modes of social ordering. In that sense they involve the deployment of utopian alternatives (Hetherington, 1997, p. 52). Heterotopia thus are seen as relational and spiritual spaces that are characterized by the crossing of thresholds and boundaries. They are spaces in which 'we' and 'the others' meet, in which the participants are willing to be confronted with and changed by one another's otherness. This relational space is a counter-site: on the one hand it mirrors and reflects the tensions that the normalizing forces in society produce, on the other hand it calls these forces in question, it neutralizes or inverts them (Moser, 2000).

\section{Heterotopia as spaces of encounter}

After this sketch of recently developed interpretations of the Foucauldian concept of heterotopia I want to explore their relevance for relations between persons with and without intellectual disability. Again I quote Edward Hall when he states: "While social inclusion policy is concerned with providing access to the (economic) [and I might add: geographical, architectural, legal and cultural. HPM] spaces of the majority, it pays little attention to the structures and attitudes that dominate in such spaces, the transformation of which people with learning disabilities arguably desire" 
(Hall, 2005, p. 113). This quote clearly demonstrates the two sides of the situation created by social inclusion policies in the last decades. It is a situation of both access and resistance. People with intellectual disability are not any more left to the control and correction of deviance and difference through 'total institutions'. However, the disciplining forces of the classical heterotopia persist. They continue to execute their power, not only in the new forms service organizations have taken in the past decennia but also in all those new sites where people with and without intellectual disability meet: neighbourhoods, businesses, sporting clubs, shops, pubs, libraries, churches, associations, public transport, etcetera.

The access to these new sites that Foucault calls 'real spaces' or 'normal spaces' generates a series of sometimes unexpected barriers that demonstrate hitherto invisible aspects of the normalizing powers of society. Lynn Fendler (2006) for instance found that "...community-building practices tend towards homogeneity and assimilation despite their explicit intentions of the contrary" (p. 315). Normality and assimilation to it are thus enforced by society. But the other side is that these new sites open up a space of encounter in which difference, prejudice and resistance invoked by the mutual strangeness can be faced up to in personal relationships. This space of encounter is not by definition subjugated to the yoke of normality. So the new situation is characterized by an ambiguous and largely indeterminable mixture of what is considered to be 'familiar' and what is considered to be 'strange', of those who are considered to be 'normal' and those who are considered to be 'deviant' or just 'different'. It offers opportunities to develop what Campbell has called a 'semiotics of exchange, an ontological decoder to recover and apprehend the life worlds of humans living peripherally' (Campbell, 2009, p. 14).

It seems to me that this analysis raises two important connected questions that I qualify as moral questions because they refer to the good of and in human relationships. The first question is how the ambiguous mixture of differing normativities can be transformed into a dialogue. And the second question is how the internal dialogue in this space of encounter may transform society's 'homotopic' thinking, the dominating conceptions of what is normal, useful, sensible, and healthy. In the next sections I will tentatively describe some ways to find an answer to these questions. 


\section{Where to find spaces of encounter}

Now where do we find these spaces of encounter in contemporary everyday social reality? Many authors do not believe that acceptance of and respect for differences can be expected of collective social structures and their political and legal arrangements. Only in a direct social environment in which people are not anonymous to one another they can separate themselves from the disciplining, assimilating and annexing forces that dominate society. In this connection Stiker (1999, p. 199) speaks of 'black markets', of a 'shadow economy' of social relationships, a social space that consists in an 'underground network' of small-scale local initiatives that runs through all state institutions, the market, the public sphere, 'civil society' and the private domain and that is not concerned with the almost sacrosanct dividing lines that are drawn in theory and practice between these areas.

The space at issue here can be described best as a space 'in between', a niche or sanctuary that would indeed be helped by a material embedding (in services, social institutions and buildings) but does not derive its existence and nourishing sources from that material embedding. The German special educationalist Dreher speaks in this connection of an 'A-topia', the space between a starting point that represents the ordinary and familiar and an uncertain final destination in which the transformation into inclusive thinking and acting will be completed (Ntourou, 2007, p. 255).

Space where people with a disability can meet others in such a way that the prejudice and resistance invoked by the mutual strangeness can be faced up to. In such a space an interaction can occur in which the uniqueness and strangeness of the partners is recognized. Their dialogue is not subjugated to the yoke of general ideas like 'ordinary everyday life', 'normal existence' or 'independent living'. It is the space where life stories are told, where they can be connected with one another and thereby can create new moral space. As a consequence, a transformation in thinking, speaking and acting can occur that invokes new meanings and a new way of acting in life and society by all those involved. Uniqueness, strangeness and communality can then develop into a configuration in which the one dimension does not overshadow or suppress the other (Ntourou, 2007, p. 157). Countering processes of marginalization and exclusion, such a space, niche or sanctuary has the potential to establish and nourish connections between people in which difference and strangeness are allowed to remain. This space can be created - and 
often arises spontaneously - in families, schools, work places, choirs, faith communities, neighbourhoods, sporting clubs and other associations, as well as in traditional protected forms of living and care. It can be organized as a fordable place in the great stream of dominant conventions and views but often it also arises spontaneously from coincidental meetings. All practices mentioned above can become for all those involved a space of encounter, a space where loneliness and social superfluity can be actively combated and a sense of belonging can flourish. Such a space is populated particularly by people who have gradually discovered or want to discover that the disruption by the strange, the unsuitable, by that what cannot be accommodated, brings its own order. These are people who want to be reminded of the fact that they themselves are strangers (Meininger, 2008). Concrete examples of this kind of spaces can be found in those encounters, places and events where 'being with' persons with intellectual disabilities is emphasized instead of 'doing something for' them. These spaces can be found where intrinsically motivated people choose to share (part of) their life with people with intellectual disabilities as for instance in the communities of l'Arche (Reinders, 2008), in buddy programs or friendship circles (Novak Amado, 1993; Perske, 1988). But also within professional care settings, schools, work places and families niches, moments and personal encounters can be found or created that disclose a space for storied dialogue. This interpretation of heterotopia is critical of the idea that non-institutional or nongovernmental voluntary organizations, 'ordinary' encounters in families, neighbourhoods, schools, workplaces, churches and civil associations or what is called 'civil society' pre-eminently and intrinsically contribute to social inclusion. This idea is a myth because all these places operate on the basis of particular conceptions of needs, care, welfare, disability and integration that not necessarily cover the needs, views, wishes and particular life styles that marginalized individuals may have (Villadsen, 2009). All of them can become spaces of encounter, but all of them are at the same time subject to normalizing and disciplining discourses. As Partington (2005) states regarding the concept of social capital: 'In relation to inclusion of people with intellectual disabilities, social capital may actually represent both cure and disease'. 'Full inclusion' is an illusion if and when it is interpreted as the outcome of a process in which the tensions produced by asymmetry and strangeness between people are completely removed. Within all these spaces of 
encounter there is just an ever continuing struggle for an interpersonal dialogue in which the forces of disciplining normalization and those of liberating humanity and their respective discourses are continually confronted, negotiated, and provisionally balanced (Michailakis \& Reich, 2009).

\section{Characteristics of spaces of encounter}

Countering processes of marginalization and exclusion, heterotopia as spaces of encounter have the potential to establish and nourish connections between people in which difference and strangeness are allowed to remain. Some characteristics of such spaces of encounter are the following (Kal, 2001, pp. 52-75; 2013; Meininger, 2010, p. 199):

a) The person with intellectual disability knows that he or she is welcome, even if he or she is not able to express joy, suffering, lack and desire in line with the prevailing codes and in recognized vocabulary. That which remains without speech and vague is not denied by actively shouting it down. Others will expose themselves to it and endure it with perseverance. Accommodation is offered to people who cannot be 'accommodated'.

b) The space is characterized by hospitality. People have time for each other Foucault mentions heterochronia, the stopping or slowing down of time, as an important principle of heterotopia (Foucault \& Miskowiec, 1986, p. 26). There is room to offer emotional support and communal activities are sought that can be experienced as meaningful by all. People are enabled to experience themselves as acting subjects and thus to develop self-esteem.

c) The space is characterized by a suspension of the goal-means rationality that is determinative not only for organized care and support but for all action in society. It is not concerned with producing 'evidence-based' effects of certain care and support methodologies, with 'making something' or 'producing something'. What counts is being present and experiencing together that which is considered to be of value.

d) In such a counter site the ideology of normality is suspended. The mutual strangeness remains a thorn in the flesh of the culture of self-sufficiency and emancipation, independence and rationality. The 'abnormal' calls in question 
this culture which is the main breeding ground of many conceptions of contemporary citizenship (Renders \& Meininger, 2011, 2012).

e) In all of this, the space of encounter is a space for dia-logue, literally, a 'speaking among', that moves among or between different logics. The dialogue derives its transforming effect not from the arrangement of a certain discourse but from its disturbing and offensive but sometimes also liberating ability to put all logics in the shade (Ntourou, 2007, pp. 253-254). That, for instance, is the transforming experience to which parents witness when they relate that life with their disabled child has taught them to look at the world and themselves in an entirely different way. And fortunately that experience is not only reserved for them.

\section{External effects of the internal dialogue}

As I stated before, an important question is how the internal dialogue in these new heterotopic spaces of encounter may transform society's 'homotopic' thinking, the dominating conceptions of what is normal, useful, sound, proper and healthy. More precisely, how does it transform our ideas about integration, community, citizenship and freedom? This is a crucial question. If the heterotopical dialogue does not lead to a transformed thinking about these fundamental conceptions, it is doomed to remain the inaccessible and purely subjective property of the few members of society that for one reason or another have come to a deeper understanding of themselves and a deeper mutual understanding in this dialogue. Then the space of encounter may become a new enclave of otherness, as distanced and segregated from the rest of society as the traditional institutions, the classical heterotopia of deviance. After presenting two case studies of inclusive activities - a theatre company and an arts and crafts organisation - Hall (2010) concludes that a key limitation of these projects "...is the lack of clear transformation of the broader structures and processes that sustain the exclusion, discrimination and abjection of people with IDs" (p. 56). Nevertheless these projects offer important opportunities for forming friendships, for gaining support within the safe settings of the rehearsal room or the workshop, and for mediated proximity to 'majority' people. Hall (2010) presumes that such 'continuous active processes of insiderness and proximity' have the potential to gradually dismantle society's deep-rooted structures of exclusion. Therefore, this transformation of 'homotopic' thinking puts us before the twofold 
challenge of making explicit the values and virtues involved in the internal dialogue of these new spaces of encounter and confronting them with the philosophies that dominate society and thereby dominate our practices of care and support as well as our research practices. In order to meet this challenge some requirements have to be fulfilled regarding both the internal processes in the new heterotopia and their relation to the broader processes in general society that are largely determined by 'homotopic' thinking.

Firstly, the internal dialogue must intentionally and explicitly be designed as a laboratory of new meaning for all participants and not as a therapeutic space. This does not preclude that such a space may have therapeutic effects for both people with and without intellectual disabilities. Primarily, however, it should be conceived as a space in which dialogue is celebrated as the only way to develop alternative modes of ordering relationships. In this context, ambiguities caused by differences between people, tensions between discourses and discordance with conventional values must be viewed as necessary preconditions for this dialogue and an opportunity for change. Secondly, in relation to broader societal processes these spaces of encounter must be 'obligatory points of passage', both in the sense that without going through and participating in them alternative modes of ordering cannot be developed and in the sense that they cannot easily be avoided or ignored. As I stated before, the new heterotopia are not bound to specific life domains or geographical places. All places, all life domains, all relationships must become an arena in which the dialogue that continually challenges the tenets of 'homotopic' thinking can flourish. Inclusion consists in the participation in such a critical dialogue.

Many policy documents and related practices, permeated as they are by 'homotopic' thinking and despite their rhetoric of inclusion, appear to recoil of such a critical dialogue. For instance, at first sight the introduction of friendship discourse in recent British policy documents could be interpreted as a weak sign of a possible transformation in 'homotopic' thinking. However, as Hughes, Redley and Ring (2011) have argued, this introduction happens without acknowledgment of the redefinition of friendship that has taken place in practice-based theological and ethical reflection and without a clear understanding of the tensions and conflicts between these redefinitions and dominating popular and philosophical conceptions of friendship. Such an evasion of dialogue may be a recipe for failure in the implementation of 
inclusion policy. Evasion of dialogue is also illustrated in practices that, under the umbrella of inclusion, in the end result in new patterns of discrimination (Hyder \& Tissot, 2013).

\section{Conclusion}

We can learn from Foucault's conceptualization of 'other places' and its subsequent reinterpretations that the rejection of segregated monocultures in total institutions was seldom associated with awareness that the normal and ordinary life in which persons with intellectual disability had to be included in many respects is a closed monoculture itself. Politics of inclusion and discourses of people with intellectual disability as 'equal citizens', 'partners' or 'autonomous clients' then easily disguise the asymmetrical power relationships to which many practices are subject. This lack of awareness may well be the reason why so many well-meant policies and practices that aim to include persons with intellectual disability or other marginalized people in mainstream society have disappointing results and often perpetuate exclusionary processes.

New interpretations of heterotopia allow for a reversal in which homotopia the 'real' and 'normal' places - are criticized as the spaces that pre-eminently exclude. In these interpretations heterotopia are represented as niches within all life domains and all public and private places. These niches are spaces of encounter and dialogue. They form a permanent practice ground for alternative social ordering. The challenge is how to establish, arrange and foster such heterotopia. It may be clear this not only requires a favorable political culture, but also a widely supported civil willingness and a personal commitment of individuals.

\section{Acknowledgements}

The author wishes to thank the members of the Dutch panel of researchers in Social Inclusion for their feedback on an early version of this paper. I am also indebted to the anonymous reviewers of the Journal of Social Inclusion (JoSI) for their thoughtful comments and suggestions. 


\section{References}

Bauman, Z. (2001). Community: Seeking safety in an insecure world. Cambridge: Polity Press.

Beadle-Brown, J., Mansell, J., Tøssebro, J., Siska, J., \& Bigby, C. (2011). Policies for a good life in the community. Paper presented at the 11th Research Conference of the Nordic Network on Disability Research, Reykjavik.

Ben-Moshe, L. (2011). The contested meaning of "Community" in discourses of deinstitutionalization and community living in the field of developmental disability. Research in Social Science and Disability, 6, 241-264.

Bray, A., \& Gates, S. (2003). Community participation for adults with an intellectual disability. Review of the literature prepared for the National Advisory Committee on Health and Disability to inform its project on services for adults with an intellectual disability. Wellington/Dunedin: Donald Beasley Institute / National Health Committee.

Burrel, B., \& Trip, H. (2011). Reform and community care: Has de-institutionalisation delivered for people with intellectual disability? Nursing Inquiry, 18(2), 174183.

Campbell, F. K. (2009). Contours of ableism: The production of disability and abledness. New York: Palgrave Macmillan.

Carey, A. C. (2011). The quest for community: Intellectual disability and the shifting meaning of community in activism. Research in Social Science and Disability, 6, 198-213.

Carlson, L. (2010). The faces of intellectual disability. Philosophical reflections. Bloomington, Indianapolis: Indiana University Press.

Clapton, J. (2009). A Transformatory ethic of inclusion. Rupturing concepts of disability and inclusion. Rotterdam/Boston/Taipei: Sense Publishers.

Clegg, J., Murphy, E., Almack, K., \& Harvey, A. (2008). Tensions around inclusion: Reframing the moral horizon. Journal of Applied Research in Intellectual Disabilities, 21(1), 81-94.

Cobigo, V., Ouellette-Kuntz, H., Lysaght, R., \& Martin, L. (2012). Shifting our conceptualization of social inclusion. Stigma Research and Action, 2(2), 7584. doi: $10.5463 /$ SRA.v1i1.10

Crisp, B. (2010). Belonging, connectedness and social exclusion. Journal of Social Inclusion, 1(2), 123-132.

Cummins, R. A., \& Lau, A. L. D. (2003). Community integration or community exposure? A review and discussion in relation to people with an intellectual disability. Journal of Applied Research in Intellectual Disabilities, 16, 145-157.

Defert, D. (2009). "Héterotopie": Tribulations d'un concept entre Venise, Berlin et Los Angeles. In M. Foucault (Ed.), Le Corps Utopique, Les Héterotopies: Textes inédits suivis d'une présentation de Daniel Defert (pp. 37-61). Paris: Nouvelles Éditions Lignes.

Dehaene, M., \& De Caulter, L. (Eds.). (2008). Heterotopia and the city: Public places in a postcivil society. Oxon, New York: Routledge.

Drinkwater, C. (2005). Supported living and the production of individuals. In S. Tremain (Ed.), Foucault and the government of disability (pp. 229-244). Ann Arbor: The University of Michigan Press.

Fendler, L. (2006). Others and the problem of community. Curriculum Inquiry, 36(3), 303-326. 
Foucault, M. (1984). Des espaces autres. AMCS, Revue d'architecture, (Octobre), 46-49.

Foucault, M. (2006). History of madness. Abingdon, Oxon: Routledge.

Foucault, M. (2009). Les héterotopies. In M. Foucault (Ed.), Le corps utopique, les héterotopies: Textes inédits suivis d'une présentation de Daniel Defert [The utopian body, the heterotopia: Unpublished texts followed by a presentation by Daniel Defert] (pp. 23-36). Paris: Nouvelles Éditions Lignes.

Foucault, M., \& Miskowiec, J. (1986). Of other spaces. Diacritics, 16(1), 22-27.

Gleeson, B. (2001). Disability and the open city. Urban Studies, 38(2), 251-265.

Gleeson, B., \& Kearns, R. (2001). Remoralising landscapes of care. Environment and Planning D: Society and Space, 19(1), 61-80.

Goffman, E. (1961). Asylums: Essays on the social situation of mental patients and other inmates. Garden City N.Y.: Anchor Books

Goodey, C. F. (2011). A history of intelligence and "Intellectual Disability". The shaping of psychology in early modern Europe. Farnham, Burlington: Ashgate.

Hall, E. (2005). The entangled geographies of social inclusion/exclusion for people with learning disabilities. Health \& Place, 11(2), 107-115.

Hall, E. (2010). Spaces of social inclusion and belonging for people with intellectual disabilities. Journal of Intellectual Disability Research, 54(supplement 1), 4857.

Hetherington, K. (1997). The badlands of modernity. Heterotopia and social ordering. London, New York: Routledge.

Holt, L. (2003). (Dis)abling children in primary school micro-spaces: Geographies of inclusion and exclusion. Health \& Place, 9(2), 119-128.

Hughes, R. P., Redley, M., \& Ring, H. (2011). Friendship and adults with profound intellectual and multiple disabilities and English disability policy. Journal of Policy and Practice in Intellectual Disabilities, 8(3), 197-206.

Hyder, E., \& Tissot, C. (2013). 'That's definite discrimination': Practice under the umbrella of inclusion. Disability \& Society, 28(1), 1-13. doi: 10.1080/09687599.2012.695579

Kahn, J. S. (2001). Modernity and exclusion. London: Sage.

Kal, D. (2001). Kwartiermaken. Werken aan ruimte voor mensen met een psychiatrische achtergrond. [Making quarters. Creating space for people with a psychiatric background]. Amsterdam: Boom.

Kal, D. (2013). Kwartiermaken [making quarters]. Retrieved from http://www.kwartiermaken.nl/english

Kitchin, R. (1998). 'Out of place', 'Knowing one's place': Space, power and the exclusion of disabled people. Disability \& Society, 13(3), 343-356.

Lalvani, P. (2013). Privilege, compromise, or social justice: Teacher's conceptualization of inclusive education. Disability \& Society, 28(1), 14-27. doi: 10.1080/09687599.2012.692028

Macfarlane, K. (2010). Social inclusion policy: Producing justice or retribution? Journal of Social Inclusion, 1(2), 133-149.

Martin, L., \& Cobigo, V. (2011). Definitions matter in understanding social inclusion. Journal of Policy and Practice in Intellectual Disabilities, 8(4), 276-282.

Meininger, H. P. (2008). The order of disturbance: Theological reflections on strangeness and strangers, and the inclusion of person with intellectual disabilities in faith communities. Journal of Religion, Disability \& Health, 12(4), 347-364. 
Meininger, H. P. (2010). Connecting stories: A narrative approach of social inclusion of persons with intellectual disability. ALTER, European Journal of Disability Research, 4(3), 190-202.

Michailakis, D., \& Reich, W. (2009). Dilemmas of inclusive education. ALTER, European Journal of Disability Research, 3(1), 24-44.

Moser, I. (2000). Against normalisation: Subverting norms of ability and disability. Science as Culture, 9(2), 201-240.

Novak Amado, A. (Ed.). (1993). Friendships and community connections between people with and without developmental disabilities. Baltimore: Paul $\mathrm{H}$. Brookes.

Ntourou, I. (2007). Fremdsein - fremdbleiben. Fremdheit und geistige behinderung eine spurensuche.[Being strange - remaining strange. Strangeness and intellectual disability - a search for traces]. Berlin: LIT Verlag.

Partington, K. (2005). What do we mean by our community? Journal of Intellectual Disabilities, 9(3), 241-251.

Perske, R. (1988). Circles of friends: People with disabilities and their friends enrich the lives of one another. Nashville: Abingdon Press.

Razack, S. H. (2002). When place becomes race. In S. H. Razack (Ed.), Race, space and the law: Unmapping a white settler society (pp. 1-20). Toronto: Between the Lines.

Reinders, H. S. (2008). Receiving the gift of friendship. Profound disability, theological anthropology, and ethics. Grand Rapids, MI, Cambridge, U.K.: William B. Eerdmans Publishing Company.

Renders, F. A., \& Meininger, H. P. (2011). Afscheid van het burgerschapsparadigma? [Farewell to the citizenship paradigm?] Nederlands Tijdschrift voor de Zorg aan mensen met verstandelijke beperkingen, 37(3), 147-167.

Renders, F. A., \& Meininger, H. P. (2012). Erkenning van verschil: Een repliek. [Recognizing difference: A reply] Nederlands Tijdschrift voor de Zorg aan mensen met verstandelijke beperkingen, 38(1), 34-40.

Snyder, S. L., \& Mitchell, D. T. (2006). Cultural locations of disability. Chicago, London: The University of Chicago Press.

Stiker, H. J. (1999). A history of disability (W. Sayers, Trans.). Ann Arbor MI: The University of Michigan Press.

Taket, A., Crisp, B. C., Nevill, A., Lamaro, G., Graham, M., \& Barter-Godfrey, S. (Eds.). (2009). Theorising social exclusion. London, New York: Routledge.

Tøssebro, J., Bonfils, I. S., Teittinen, A., Tideman, M., Traustadóttir, R., \& Vesala, H. T. (2012). Normalization fifty years beyond - Current trends in the Nordic countries. Journal of Policy and Practice in Intellectual Disabilities, 9(2), 134146.

UN. (2006). Convention on the rights of persons with disabilities. Retrieved from http://www.un.org/disabilities/

Verdonschot, M. M. L., De Witte, L. P., Reichrath, E., Buntinx, W. H. E., \& Curfs, L. M. G. (2009a). Community participation of people with an intellectual disability: a review of empirical findings. Journal of Intellectual Disability Research, 53(4), 303-318.

Verdonschot, M. M. L., De Witte, L. P., Reichrath, E., Buntinx, W. H. E., \& Curfs, L. M. G. (2009b). Impact of environmental factors on community participation of persons with an intellectual disability: A systematic review. Journal of Intellectual Disability Research, 53(1), 54-64. 
Villadsen, K. (2009). The 'human' touch. Voluntary organizations as rescuers of social policy? Public Management Review, 11(2), 217-234.

Villadsen, K.,\& Wyller, T. (2009). From the spatial heterotopos to the deterritorialized (heterotopic) hope. In T. Wyller (Ed.), Heterotopic citizen. New research on religious work for the disadvantaged (pp. 218-229). Göttingen: Vandenhoeck \& Ruprecht.

Wyller, T. (Ed.). (2009). Heterotopic citizen. New research on religious work for the disadvantaged (Vol. 4). Göttingen: Vandenhoeck \& Ruprecht.

\section{Biographical Notes}

Herman P. Meininger is emeritus professor of Ethics and Social Inclusion of Persons with Intellectual Disabilities at the Willem van den Bergh Chair, established by the service provider's Heeren Loo at VU University, Amsterdam, the Netherlands. He served for more than 30 years as a chaplain, coordinator of multidisciplinary staff, research fellow and policy advisor in Dutch service organizations. He published three books and more than hundred articles on theology, ethics and social inclusion in relation to (care and support for) people with intellectual disability. 